Federal Reserve Bank of Minneapolis

Research Department

\title{
How Good Are Standard Debt Contracts? Stochastic Versus Nonstochastic Monitoring in a Costly State Verification Environment
}

\author{
John H. Boyd and Bruce D. Smith*
}

Working Paper 512

Revised December 1993

\begin{abstract}
We investigate ex-ante efficient contracts in an environment in which implementation is costless. In this environment, standard debt contracts will typically not be optimal. Optimal contracts may involve defaults, even in states in which the borrower is fully able to repay. We then examine the welfare costs of arbitrarily restricting the set of feasible contracts to standard debt contracts. When model parameters are calibrated to realistic values, the welfare loss from exogenously imposing this restriction is extremely small. Thus, if the implementation costs are actually nontrivial (as seems likely), standard debt contracts will be (very close to) optimal.
\end{abstract}

*Boyd, Federal Reserve Bank of Minneapolis and University of Minnesota; Smith, Federal Reserve Bank of Minneapolis and Cornell University. We thank Doug Diamond, Ed Green, Ellen McGrattan, Janet Mitchell, John Moore, Andy Winton, and an anonymous referee for helpful comments, with the usual disclaimer absolving them from responsibility for remaining errors. Joel Krueger provided excellent computational assistance. The views expressed herein are those of the authors and not necessarily those of the Federal Reserve Bank of Minneapolis or the Federal Reserve System. 


\begin{abstract}
We investigate ex-ante efficient contracts in an environment in which implementation is costless. In this environment, standard debt contracts will typically not be optimal. Optimal contracts may involve defaults, even in states in which the borrower is fully able to repay. We then examine the welfare costs of arbitrarily restricting the set of feasible contracts to standard debt contracts. When model parameters are calibrated to realistic values, the welfare loss from exogenously imposing this restriction is extremely small. Thus, if implementation costs are actually nontrivial (as seems likely), standard debt contracts will be (very close to) optimal.
\end{abstract}




\section{Introduction}

Most theoretical analyses of financial contracting suggest that optimal financial contracts should have a relatively complex structure. Even in simple environments with risk neutral agents and straightforward informational asymmetries, theory suggests that optimal financial contracts should incorporate a rich set of state contingencies, and in addition should potentially allow for resources to be transferred on the basis of extraneous randomization.

For example, one of the simplest financial contracting environments-the costly ex-post state verification (CESV) environment of Townsend (1979) with risk neutral agents-has the following implications regarding optimal contracts. The contract specifies a fixed repayment (principal plus interest). If this is not repaid, bankruptcy proceedings are initiated. Whether or not bankruptcy (verification) costs are born is determined by extraneous (and contractually agreed upon) randomization. Resources transferred under the contract depend on these extraneously randomized outcomes. In addition, bankruptcy proceedings can be initiated because the debtor fails to repay principal plus interest, even though he is fully able to do so. The debtor may retain resources when this occurs.

These theoretical implications regarding optimal financial contracts stand in stark contrast to observed contracts, which frequently contain few state contingencies, and rarely explicitly call for extraneous randomization of payments. The most obvious example is the so-called "standard debt contract," which calls for noncontingent repayment of principal plus interest. When this repayment does not occur, bankruptcy proceedings are initiated (with probability one), and all resources are transferred to the holders of claims on the debtor. 
Why do observed contracts contain relatively limited state contingencies-and relatively little provision for extraneous randomization-when theory suggests that this is a sub-optimal outcome? We consider this issue in a model in which "lenders" supply funds to "borrowers" who must make repayments contingently, depending on the success of the projects that are funded by their loans. Lenders can observe the outcomes of these projects only at some cost. This type of CESV model was originally developed by Townsend (1979), and was subsequently extended by Diamond (1984), Gale and Hellwig (1985), and Williamson $(1986,1987)$ to consider exactly the problem of minimizing the expected costs associated with verification of the borrower's situation. The latter authors showed that, when agents are risk neutral and state verification is done nonstochastically, the optimal contract is a standard debt contract. More specifically, the borrower either repays principal plus interest fully (in which case no state verification is required), or else "defaults" and turns all proceeds of the project over to the lender. In this case the lender must "monitor" to verify that everything has been turned over to him. The latter event is associated with bankruptcy, and a standard debt contract minimizes expected bankruptcy (verification) costs-if monitoring is done nonstochastically. ${ }^{1}$

The Diamond (1984), Gale and Hellwig (1985), and Williamson (1986, 1987) results depend upon the assumption that state verification must proceed nonstochastically. In some respects (but not all), this turns out to be a strong assumption. When costly verification of project outcomes can be done stochastically, optimal financial contracts have substantially different, and more complex, features. (Stochastic monitoring is considered by Border and Sobel 1987, Townsend 1988, Mookherjee and Png 1989, and Bernanke and Gertler 1989.) First, optimal contracts generally 
specify-in advance-provisions for a certain amount of debt forgiveness. The extent of this forgiveness will typically depend on the extraneously randomized decision about whether or not to verify the borrower's announcements regarding the project outcome. Second, it is possible that an optimal contract specifies contingencies under which a borrower can default and still retain some resources even if it is publicly known that complete repayment of debts is feasible. ${ }^{2}$

If ideal contracts-stating a full set of state contingencies, and allowing arbitrary randomization of monitoring - were costless to write and enforce, we would not then expect to see the extensive use of standard debt contracts. And yet such contracts are the norm. Therefore we pose the following question: what is the welfare cost associated with exogenously-and suboptimally-prohibiting the use of stochastic verification in a CESV environment? In answering this question, we address two issues. First, if stochastic verification-and its associated contractual complexities-are desirable, we can quantify the social benefits produced. And second, if the gains associated with the use of such clauses in an ideal world are small-as we find they are-this suggests that standard debt contracts are quite likely to be (nearly) optimal in practice when one takes account of the difficulties associated with implementing and enforcing contracts which contain explicit provisions for randomization. Or, in other words, even minor features of reality that are omitted from the model could easily render it optimal to employ standard debt contracts.

Our vehicle for analyzing these issues is a minor modification of the model of Border and Sobel (1987), which results in essentially the simplest possible CESV model with borrowing and lending. No restrictions are placed on the contracts that can be written other than those implied by the environment. We then analyze ex-ante 
efficient, incentive compatible contracts, with and without stochastic monitoring. We show that optimal contracts with stochastic monitoring often exhibit a form of debt forgiveness, and may call for the initiation of bankruptcy-as well as some debt forgiveness-even though the borrower is able to repay in full. Optimal contracts without stochastic monitoring display neither feature.

To determine the welfare loss associated with exogenously (and here suboptimally) prohibiting randomization, we calibrate the model using U.S. data, and numerically solve the calibrated model for the optimal contracts-with and without stochastic monitoring. We find that the welfare loss from suboptimally imposing nonstochastic monitoring is about $0.003 \%$ to $0.03 \%$ (and certainly less than $0.12 \%$ ) of beginning firm assets. This loss is tiny compared to the estimated welfare losses that result from any widely levied tax in the United States. Thus while nonstochastic monitoring may be suboptimal, we estimate that the losses resulting from its use are extremely small. This finding has a corollary: any implementation or enforcement costs associated with stochastic monitoring are likely to change the welfare ranking of the two contracting technologies. Numerous authors (e.g., Allen and Gale 1992) have noted that such costs are likely to be nontrivial, since the lender always prefers not to monitor-after the fact-when contracts are incentive compatible ex ante.

An additional finding that emerges from the calibrated model is that, while standard debt contracts are not theoretically optimal in CESV environments, optimal contracts with stochastic monitoring closely resemble such contracts-with a certain amount of debt forgiveness-in many respects. This conclusion is of some independent interest, as it tends to confirm that standard debt contracts are "almost optimal contracts ${ }^{n}$ in practice. ${ }^{3}$ 


\section{Discussion}

The CESV environment with risk neutral agents is one of the simplest, and most widely used models of financial contracting. And, as we show, even this environment yields the result that optimal contracts build in a substantial degree of state contingency, and have the feature that state contingent payments may be extraneously randomized. Moreover, optimal contracts may call for the initiation of bankruptcy proceedings-and some debt forgiveness-even when the borrower is fully able to repay principal plus interest. ${ }^{4}$ The level of complexity of these contracts, of course, is far beyond what is observed in practice.

Since we consider only situations where contracts are costlessly written and enforced, our analysis is silent on issues of contract renegotiation, either privately or in court. Yet, we believe our findings have implications for the (as yet unresolved) issue of whether contractually agreed upon absolute priority clauses should be enforced in bankruptcy proceedings. (Recent studies on this topic include Harris and Raviv 1991 and Aghion, Hart, and Moore 1992.) In the model environment, standard debt contracts, if enforced, respect the absolute priority of debt claims in the following sense: in bankruptcy states, the borrower's wealth is always reduced to zero. However, the more complicated optimal contracts with stochastic verification often do not display this feature. Now, we conclude from the calibration exercises that standard debt contracts are "almost optimal, " even abstracting from enforcement issues. In the model environment, therefore, the same conclusion would hold for the absolute priority of debt claims, as defined above.

Finally, we note that our results (and particularly the characterization of an optimum that we borrow from Border and Sobel 1987), depend heavily on the 
assumption that agents are risk neutral. For corporate borrowing, which is what we investigate empirically, this seems natural since corporations are typically modeled as risk neutral. Also we note that, with risk-averse agents, there is no presumption that standard debt contracts are optimal, even with nonstochastic monitoring (see Townsend 1979). Thus risk-neutrality seems appropriate for our purposes.

The remainder of the paper proceeds as follows. Section I describes the environment, and summarizes the Border and Sobel characterization of optimal stochastic monitoring. Section II describes when bankruptcy may occur, even though borrowers are fully able to repay. Sections III and IV describe the calibration of the model, and the results we obtain on the welfare losses from prohibiting stochastic verification. Section V concludes.

\section{The Model}

In this section we describe the optimal (ex ante) contracting problem of an agent who must raise funds externally in the presence of a costly-state-verification problem. Our formulation mimics that of Border and Sobel (1987) in several respects, and we retain their notation wherever possible.

There are several risk-neutral borrowers, who each have access to an investment project that requires one unit of funds to operate. The owner of the project is assumed to be endowed with $\alpha \in[0,1)$ units of funds (which will represent equity in the project), and must raise $1-\alpha$ units externally. These funds are obtained from lenders. Lenders either invest in projects, or in a safe alternative asset paying the sure gross return $\rho$, which is taken as given. Lenders are also assumed 
to be risk neutral, so that borrowers must at least deliver an expected return of $\rho$ per unit on any funds they obtain. We define $\mathrm{R} \equiv \rho(1-\alpha)$.

A funded project pays a random return $x_{i}$ in state $i ; i=1, \ldots, n$. We order the states so that $x_{1}<x_{2}<\ldots<x_{n}$, and we let $h_{i} \equiv \operatorname{prob}\left(x=x_{i}\right)$. The project return is, of course, observed ex post by its owner. For anyone else, the project return can only be observed by expending $\gamma$ units of resources. We assume that $0<$ $\gamma<\mathrm{x}_{1}$, so that projects always return enough to cover their verification cost. We also assume that $R>x_{1}$.

Events unfold in two stages. First, project owners announce contracts specifying post-state payments to potential lenders. Lenders lend to those offering the most attractive (highest expected return), incentive compatible contracts. After funds are obtained, the project is operated and the state is revealed to the project owner. Then the project owner announces a state, verification of the announcement may occur, and the appropriate state contingent payments are made. We assume that lenders have no funds in the second stage (their funds have all been lent or consumed), so that all resources must come from project returns-including the resources used in state verification.

\section{Contracts}

A contract specifies several objects. First, if the borrower announces that state $\mathrm{j}$ has occurred, the contract specifies that monitoring will occur with probability $\mathrm{P}_{\mathrm{j}} \in[0,1]$. If monitoring does occur and the true state is $\mathrm{i}$, the borrower pays the lender $\mathrm{f}_{\mathrm{ij}} \in\left[\gamma, \mathrm{x}_{\mathrm{i}}\right]$ (since the payment must at least cover the costs of state 
verification, and cannot exceed $x_{i}$ ). If monitoring does not occur, the payment is $t_{j} \in\left[0, x_{j}\right]$ (since again the lender has no resources, $t_{j} \geq 0$ must hold).

Assuming that contracts are designed to induce truthful revelation of the state, ${ }^{5}$ in state $i$ the borrower receives $x_{i}$, pays $t_{i}$ with probability $\left(1-p_{i}\right)$, and pays $f_{i i}$ with probability $p_{i}$. Truthful revelation of the state requires that, for all $i, j$,

$$
x_{i}-\left[\left(1-p_{i}\right) t_{i}+p_{i} f_{i j}\right] \geq\left(1-p_{j}\right)\left(x_{i}-t_{j}\right)+p_{j}\left(x_{i}-f_{i j}\right) .
$$

Also, in order to obtain any funds, the borrower must offer an expected return of at least $\rho$ on the $1-\alpha$ funds borrowed. This requires that

$$
\sum_{i} h_{i}\left[\left(1-p_{j}\right) t_{i}+p_{i} f_{i i}-p_{i} \gamma\right] \geq R .
$$

In addition, nonnegativity of consumption requires that, for all $\mathbf{i}, \mathbf{j}$,

$$
\begin{aligned}
& \text { (3) } \mathrm{t}_{\mathrm{i}} \in\left[0, \mathrm{x}_{\mathrm{i}}\right] \\
& \text { (4) } \mathrm{f}_{\mathrm{ij}} \in\left[\gamma, \mathrm{x}_{\mathrm{i}}\right] .
\end{aligned}
$$

We assume that borrowers choose a contract-that is a schedule $\left(\mathrm{p}_{\mathrm{i}}, \mathrm{t}_{\mathrm{i}}, \mathrm{f}_{\mathrm{ij}}\right)-$ to maximize their own expected utility subject to constraints (1)-(4); or in other words to solve the problem

(P.1) $\quad \max \sum_{i} h_{i}\left[x_{i}-\left(1-p_{j}\right) t_{i}-p_{i} f_{i i j}\right]$

subject to (1)-(4). Observe that it is obviously the case that an optimum sets $f_{i j}=$ $x_{i}$ for all $i \neq j$.

Following Border and Sobel, we transform this problem as follows. Define $f_{i} \equiv f_{i i}$, and let

$$
r_{i} \equiv\left(1-p_{i}\right) t_{i}+p_{i} f_{i}
$$


be the expected payment by the borrower, conditional on the occurrence of state $i$. Finally, let $q_{i} \equiv 1-p_{i}$. The problem (P.1) can then be rewritten as

(P.2) $\quad \max \sum_{i} h_{i}\left(x_{i}-r_{i}\right)$

subject to

(1') $\quad x_{i}-r_{i} \geq q_{j}\left(x_{i}-t_{j}\right)$ for all $i, j$

(2') $\quad \sum_{i} h_{i}\left[r_{i}-\gamma\left(1-q_{i j}\right)\right] \geq R$

(3') $\quad \mathrm{q}_{\mathrm{i}} \mathrm{i}_{\mathrm{i}}+\left(1-\mathrm{q}_{\mathrm{i}}\right) \gamma \leq \mathrm{r}_{\mathrm{i}} \leq \mathrm{x}_{\mathrm{i}}$ for all $\mathrm{i}$

(4') $\quad 0 \leq \mathrm{t}_{\mathrm{i}} \leq \mathrm{x}_{\mathrm{i}}$ for all $\mathrm{i}$

by choice of a schedule $\left(r_{i}, t_{i}, q_{i j}\right)$. We observe that $\left(3^{\prime}\right)$ is equivalent to $f_{i} \in\left[\gamma, x_{i}\right]$, and that we have used $f_{i j}=x_{i}$ for all $j \neq i$ in $\left(1^{\prime}\right)$.

Our model is a minor modification of that in Border and Sobel: in particular, payments to lenders must cover monitoring costs when monitoring occurs $\left(f_{i} \geq \gamma\right)$, and we consider a slightly different optimization problem than they do. These modifications of the analysis are sufficiently small that it is not surprising that the following theorem from Border and Sobel survives intact.

Theorem (Border and Sobel). Suppose that $\left\{\mathrm{r}_{\mathrm{i}}, \mathrm{t}_{\mathrm{i}}, \mathrm{q}_{\mathrm{i}}\right\}_{\mathrm{i}=1}^{\mathrm{n}}$ solves (P.2). Then, if $\mathrm{i}>\mathrm{j}$,

(a) $r_{i} \geq r_{j}$, and equality holds iff $q_{i}=q_{j}=1$.

(b) $x_{i}-r_{i} \geq x_{j}-r_{j}$, and equality holds iff $x_{i}=r_{i}$.

(c) $q_{j} \leq q_{i}$, and equality holds iff $q_{j}=1$ or $q_{i}=0$.

(d) $t_{i} \geq t_{j}$, and equality holds iff $q_{j}=1$. 
In addition,

(e) $\mathrm{q}_{\mathrm{n}}=1$

(f) For each $\mathrm{i}>1$, there exists a $\mathrm{j}$ such that $\left(1^{\prime}\right)$ holds with equality for that $(\mathrm{i}, \mathrm{j})$ pair.

(g) If $\mathrm{q}_{\mathrm{j}}<1$, there is some $\mathrm{i}>\mathrm{j}$ so that $\left(1^{\prime}\right)$ holds with equality for that $(\mathrm{i}, \mathrm{j})$ pair.

(h) If $\left(1^{\prime}\right)$ holds with equality for some pair $(i, j)$ and $q_{i} \in(0,1)$, then $i>j$.

(i) (1') holds with equality for $\mathrm{n}$ and $\mathrm{n}-1$.

(j) If $\bar{i} \equiv \max \left\{j: q_{i j}<1\right\}$, then (1') holds with equality for $\bar{i}+1$ and $\bar{i}$.

(k) If $\underline{i} \equiv \min \left\{i: q_{i}>0\right\}$ and $q_{1}<1$, then $x_{j}=r_{j}$ iff $j \leq \underline{i}$.

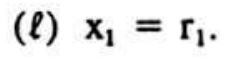

The proof of the theorem is identical to that in Border and Sobel (1987), except that their lemma 2 is replaced by

LEMMA. For each $j, t_{j}=x_{j}$ or $r_{j}=q_{j} t_{j}+\left(1-q_{j}\right) \gamma$, or both.

The proof of the lemma is identical to that of Border and Sobel's lemma 2. The lemma states that $f_{i}=\gamma$ if $r_{i}<x_{i}$; that is, the payment from the borrower to the lender is as small as possible when monitoring occurs (and reveals truthful announcement of the state), if the borrower retains anything at all in state $i$.

\section{Nonstochastic Monitoring}

Our interest is in contrasting solutions to the problem (P.2) with solutions to the nonstochastic monitoring problem, which constrains $p_{i} \in\{0,1\}$. We refer to this problem as 
(P.3) $\quad \max \sum_{i} h_{i}\left(x_{i}-r_{i}\right)$

subject to $\left(1^{\prime}\right)-\left(4^{\prime}\right)$ and

(5) $\mathrm{q}_{\mathrm{i}} \in\{0,1\}$ for all $\mathrm{i}$.

Solutions to this problem deliver so-called "standard debt contracts:" $x_{i}=r_{i}$ if $\mathrm{q}_{\mathrm{i}}=0$, and $\mathrm{q}_{1}=\mathrm{q}_{2}=\ldots=\mathrm{q}_{\mathrm{i}}=0 ; \mathrm{q}_{\mathrm{i}}=1$ for all $\mathrm{i}>\mathrm{i}$. In such a contract the borrower can be viewed as making the payment of "interest plus principal" $-r_{i+1}-$ if possible, and as "defaulting" if this is not possible. In the event of a default the lender monitors the project, and retains the complete (net of monitoring cost) value of it. Thus optimal contracts solving the nonstochastic monitoring problem (P.3) display "absolute priority" in the sense discussed in the introduction. We now show that this is not the case for solutions to the stochastic monitoring problem (P.2).

\section{Optimal Stochastic Monitoring}

We now show that solutions to the stochastic monitoring problem (P.2) may result in debt forgiveness, and result in bankruptcy even in states of nature in which the borrower is able to repay in full. Solutions to the nonstochastic monitoring problem (P.3) do not display either of these features. Comparing the maximized value of the objective functions in (P.2) and (P.3) amounts to evaluating the costs-in this environment-of exogenously imposing the use of standard debt contracts (and thus prohibiting these more complicated contractual features).

For simplicity of exposition, we now assume that there are only three states $(n=3)$. Since solutions to (P.2) satisfy $x_{1}=r_{1}$, part (e) of the Border and Sobel theorem implies that at least three states are necessary in order to observe the suboptimality of precluding debt forgiveness-as we now define that term. 
We henceforth refer to a state with $\mathrm{q}_{\mathrm{i}}<1\left(\mathrm{p}_{\mathrm{i}}>0\right)$ as a default state. For states with $i \geq \bar{i}+1$ (and hence with $q_{i}=1$ ), we refer to the (common) repayment $\mathbf{r}_{\mathrm{i}+1}$ as principal plus interest. By definition, contractual debt forgiveness occurs when there exists a state $i$ which is a default state $\left(q_{i}<1\right)$, when $r_{i}<r_{i+1}$, and when $x_{i}>r_{i}$. In other words, contractual debt forgiveness occurs when the borrower repays something less than promised principal plus interest $\left(r_{i}<r_{i+1}\right)$ and yet expects to retain something $\left(x_{i}>r_{i}\right)$. Also, we will say that strong contractual debt forgiveness occurs if there is a default state $i$ with $x_{i} \geq r_{i+1}>r_{i}$. In such a state it is feasible for the borrower to fully repay principal plus interest. Yet the borrower does not do so, and still expects to retain something $\left(x_{i}>r_{i}\right)$.

The lemma, and the Border and Sobel theorem, indicate that contractual debt forgiveness will typically be observed. ${ }^{6}$ As we will demonstrate, however, strong contractual debt forgiveness can also easily occur in solutions to (P.2). All of the statements that follow apply to the problem (P.2) when $n=3$. It is useful to begin with the following preliminary results.

Result 1. Suppose that

(A.1) $h_{1}\left[1+\gamma /\left(x_{2}-x_{1}\right)\right]<\min [R, 1]$

and

(A.2) $\mathrm{x}_{2}>\left\{\mathrm{R}-\mathrm{h}_{1} \mathrm{x}_{1}\left[1+\gamma /\left(\mathrm{x}_{2}-\mathrm{x}_{1}\right)\right]\right\} /\left\{1-\mathrm{h}_{1}\left[1+\gamma /\left(\mathrm{x}_{2}-\mathrm{x}_{1}\right)\right]\right\}$

hold. Then it is feasible to set $q_{2}=1$.

Result 1 states conditions under which it is feasible for state 2 not to be a default state in the problem (P.2). 
Proof. It is straightforward to check that the following contractual terms satisfy $\left(1^{\prime}\right)$ and $\left(2^{\prime}\right)$ :

$$
\begin{aligned}
& \mathrm{q}_{1}=\left(\mathrm{x}_{2}-\mathrm{r}_{2}\right) /\left(\mathrm{x}_{2}-\mathrm{x}_{1}\right) \\
& \mathrm{q}_{2}=\mathrm{q}_{3}=1, \quad \mathrm{r}_{1}=\mathrm{x}_{1} \\
& \mathrm{r}_{2}=\mathrm{r}_{2}^{*} \equiv\left\{R-\mathrm{h}_{1} \mathrm{x}_{1}\left[1+\gamma /\left(\mathrm{x}_{2}-\mathrm{x}_{1}\right)\right]\right\} /\left\{1-\mathrm{h}_{1}\left[1+\gamma /\left(\mathrm{x}_{2}-\mathrm{x}_{1}\right)\right]\right\}
\end{aligned}
$$

and $r_{3}=r_{2}^{*}$. This contract is feasible if the value of $r_{2}$ given by (7) satisfies $r_{2} \in$ $\left[0, x_{2}\right]$. But this is implied by (A.1) and (A.2). Q.E.D.

Result 2. Suppose that (A.1) and (A.2) hold. Then an optimum has $r_{2}<x_{2}$.

Proof. Suppose to the contrary that an optimum has $r_{2}=x_{2}$. Parts (a) and $(\ell)$ of the Border and Sobel theorem assert that $r_{1}=x_{1}$, and $r_{3} \geq r_{2}=x_{2}$. Then the expected utility of the borrower is $h_{3}\left(x_{3}-r_{3}\right) \leq h_{3}\left(x_{3}-x_{2}\right)$.

Now set contractual terms as in the proof of result 1 . This contract delivers the borrower an expected utility level of $h_{3}\left(x_{3}-r_{2}\right)+h_{2}\left(x_{2}-r_{2}^{2}\right)>h_{3}\left(x_{3}-x_{2}\right)$ [by (A.2)]. This contradicts the optimality of a contract with $r_{2}=x_{2}$. Q.E.D.

We are now prepared to derive conditions under which solutions to (P.2) (with $n=3$ ) display strong contractual debt forgiveness. To do so, we begin by stating several conditions that these solutions satisfy. All of our statements assume that (A.1) and (A.2) hold.

Result 3. If (A.1) and (A.2) hold, the solution to (P.2) satisfies

(8) $q_{1}=\left(x_{2}-r_{2}\right) /\left(x_{2}-x_{1}\right)$

(9) $\mathrm{q}_{2}=\left(\mathrm{x}_{3}-\mathrm{r}_{3}\right) /\left(\mathrm{x}_{3}-\mathrm{t}_{2}\right)$ 
(10)

$$
t_{2}=\left[r_{2}-\left(1-q_{2}\right) \gamma\right] / q_{2}
$$

$r_{1}=x_{1}$ and $q_{3}=1$.

Proof. $\mathrm{r}_{1}=\mathrm{x}_{1}$ and $\mathrm{q}_{3}=1$ are parts $(\mathrm{e})$ and $(\ell)$ of the Border and Sobel theorem. Parts ( $f)-(j)$ of the same theorem and lemma 20 of Border and Sobel imply that the binding incentive constraints are between states $(1,2)$, and states $(2,3)$. Thus (8) and (9) hold. Finally, the lemma implies (10) if $t_{2}<x_{2}$. But $t_{2}<x_{2}$ is implied by Result 2. Q.E.D.

Solving (9) and (10) yields the equivalent conditions

(9') $q_{2}=\left[x_{3}-\gamma-\left(r_{3}-r_{2}\right)\right] /\left(x_{3}-\gamma\right)$

$\left(10^{\prime}\right) \quad t_{2}=\left(r_{2} x_{3}-\gamma r_{3}\right) /\left(x_{3}-\gamma-r_{3}+r_{2}\right)$.

Since $x_{3}>x_{1}>\gamma, q_{2} \in[0,1]$ iff $r_{3} \in\left[r_{2}, x_{3}\right] . q_{2}<1$ holds iff $r_{2}<r_{3}$. In addition, the expected return constraint $\left(2^{\prime}\right)$ may be written as (using $r_{1}=x_{1}$ ),

$$
h_{2} r_{2}+h_{3} r_{3}=R-h_{1} x_{1}+\gamma\left[h_{1}\left(1-q_{1}\right)+h_{2}\left(1-q_{2}\right)\right] \text {. }
$$

Substituting (8) and $\left(9^{\prime}\right)$ into (11) and rearranging terms gives

$$
r_{2}=\psi_{0}-\psi_{1} r_{3}
$$

where

$$
\begin{aligned}
& \psi_{0} \equiv\left[R-h_{1} x_{1}-\gamma h_{1} x_{1} /\left(x_{2}-x_{1}\right)\right] /\left\{h_{2}\left[1+\gamma /\left(x_{3}-\gamma\right)\right]-h_{1} \gamma /\left(x_{2}-x_{1}\right)\right\} \\
& \psi_{1} \equiv\left[h_{3}-h_{2} \gamma /\left(x_{3}-\gamma\right)\right] /\left\{h_{2}\left[1+\gamma /\left(x_{3}-\gamma\right)\right]-h_{1} \gamma /\left(x_{2}-x_{1}\right)\right\} .
\end{aligned}
$$

It is straightforward to show that (A.1) and (A.2) imply that

$$
\psi_{0} /\left(1+\psi_{1}\right)>0
$$


Moreover, since $r_{3} \geq r_{2}$ must hold, $r_{3}$ must satisfy

$$
\psi_{0} /\left(1+\psi_{1}\right) \leq r_{3} \leq x_{3} .
$$

In addition, $q_{1} \in[0,1]$ requires that $r_{2} \in\left[x_{1}, x_{2}\right]$ be satisfied. Then, from (12),

$$
x_{1} \leq \psi_{0}-\psi_{1} r_{3} \leq x_{2}
$$

must hold.

The problem of a borrower can now be written as

$$
\max h_{2}\left(x_{2}-r_{2}\right)+h_{3}\left(x_{3}-r_{3}\right)=h_{2} x_{2}+h_{3} x_{3}-h_{2} \psi_{0}-r_{3}\left(h_{3}-h_{2} \psi_{1}\right)
$$

subject to (15) and (16). It is easy to show that $\left(\psi_{0}-x_{1}\right) / \psi_{1}>\psi_{0} /\left(1+\psi_{1}\right)$ holds, and (A.2) implies that $x_{3}>x_{2}>\psi_{0} /\left(1+\psi_{1}\right)$. Thus the constraint set for problem (P.4) is nonempty.

\section{Result 4. Suppose that}

$$
h_{2} \psi_{1}>h_{3}
$$

holds. Then the solution to (P.4) has

$$
r_{3}=\min \left[x_{3},\left(\psi_{0}-x_{1}\right) / \psi_{1}\right], \quad r_{3}>r_{2}, \quad \text { and } q_{2}<1
$$

Proof. That (17) implies (18) is obvious. $r_{3}>r_{2}$ follows from $\left(\psi_{0}-\right.$ $\left.\mathrm{x}_{1}\right) / \psi_{1}>\psi_{0} /\left(1+\psi_{1}\right),(12)$, and (15). $\mathrm{q}_{2}<1$ is implied by $\left(9^{\prime}\right)$ and $\mathrm{r}_{3}>\mathrm{r}_{2}$. Q.E.D.

Result 4 asserts that if (A.1), (A.2), and (17) hold, a solution to (P.4) has state 2 being a default state. It is feasible to repay principal plus interest in state 2 iff $x_{2} \geq$ $r_{3}$. This condition, in turn, holds iff,

$$
x_{2} \geq\left(\psi_{0}-x_{1}\right) / \psi_{1}
$$


We have now established the following proposition.

PRoposition 1. The solution to (P.4) displays strong contractual debt forgiveness if (A.1), (A.2), (17), and (19) hold.

It is easy to produce parameter values that satisfy all of these conditions. For instance, setting $h_{1}=h_{2}=h_{3}=1 / 3, \gamma=0.2, x_{1}=0.4, x_{2}=0.6, x_{3}=0.8$, and $R=0.41$ is one example that does so.

Proposition 1 describes sufficient conditions for the solution to (P.2) (with $n=3$ ) to display strong contractual debt forgiveness. As it turns out, these sufficient conditions are quite often satisfied by the data. We now turn to an empirical investigation of the costs of exogenously imposing the use of standard debt contracts in this environment.

\section{Calibration}

In this section we calibrate the parameters of the model using U.S. data. The parameters are the monitoring cost $(\gamma)$, the ratio of borrower's equity to assets $(\alpha)$, the alternative risk-free gross interest rate $(\rho)$, and the return distributions on projects $\underline{x}=\left[x_{1}, x_{2}, \ldots, x_{n}\right], \underline{h}=\left[h_{1}, h_{2}, \ldots, h_{n}\right]$. For each set of parameters we choose a "best guess estimate" and a "conservative estimate." A conservative estimate is one which is likely to give the greatest gain to stochastic monitoring that we can justify on the basis of available empirical information.

Having chosen calibrated parameter values, we then numerically solve the problems (P.2) and (P.3), and compute the gains from stochastic monitoring (or, put 
another way, the deadweight losses resulting from exogenously imposing the use of standard debt contracts).

\section{A. Monitoring Costs}

As is widely recognized, costly-state-verification models are a way of deriving bankruptcy costs from more primitive assumptions. Banknuptcy costs in the model are driven by the monitoring cost $\gamma$. Bankruptcy costs have been heavily studied in the finance literature, the seminal work being by Warner (1977). Warner found, for a sample of railroad firms, that bankruptcy costs averaged about $1 \%$ of total assets. Subsequent researchers have obtained somewhat higher estimates. For example, based on a sample of firm failures in New York state, White (1983) concluded that $\gamma$ was about $3 \%$ of assets for firms that liquidated, and $1.7 \%$ of assets for firms that reorganized. For a sample of industrial firms, Altman (1984) estimated $\gamma$ to be about $6 \%$; the highest estimate we have found in the literature. For purposes of calibration, we assume a "best guess" value of $\gamma$ of $3.5 \%$ of assets, and a "conservative estirnate" of $10 \%$ of assets. ${ }^{7}$

\section{B. Ratio of Equity to Assets}

We consider 10 industries chosen at random from the Compustat Annual Master data set. For each industry data were pooled over time and across firms. We then computed the average fraction of total assets financed with equity in each industry, $\alpha$. The results are reported in table 1. For this parameter we did not select a "best guess" or "conservative" estimate. Instead, we will solve (P.2) and (P.3) for 
all 10 industries. This will give a sense of how sensitive are the results to $\alpha$, since $\alpha$ varies from 0.306 to 0.584 in the sample.

\section{Risk-Free Rate}

Since lenders are risk-neutral in the model, a risk-free real interest rate is the appropriate opportunity cost of funds. We chose the real interest rate to be the threemonth treasury bill rate, less the rate of change in the implicit GNP defiator, geometrically averaged over the period 1972-91. The result was a risk-free real gross rate of return of 1.0168. Of course, then, for each solution of (P.2) and (P.3), $\mathrm{R}=1.0168(1-\alpha)$, with $\alpha$ corresponding to each of the values in table 1 .

\section{Project Return Distributions}

The project return variable $x$, is defined as the rate of return on total assets (inclusive of extraordinary gains and losses), before the payment of taxes and interest expenses. This corresponds most nanually to the model specification, where $\mathrm{x}$ is a prepayment return, and where the size of a project is normalized to one. As before, return distributions for $x(x)$ were separately estimated for the same 10 industries listed in table 1 using the Compustat Annual Master data set. For each industry, data were pooled over time and across firms.

Within an industry, we first found the highest overall return realization in the

data, $x_{n}$, and the lowest, $x_{\min }$. The distance between $x_{a}$ and $x_{\operatorname{mix}}$ was then divided into 10 intervals of equal length, corresponding to discrete return states. Then, all return observations were assigned to 1 of the 10 states and located at the mid-point of the interval. A probability was assigned to each state according to its empirical 
frequency. Table 1 shows the first and second moments of the raw and transformed data; clearly the two are always quite close.

There are significant problems in obtaining usable return data for firms which have gone into reorganization or liquidation. Some data bases (including the one employed here) delete all data for firms which have failed, including historical data. Even when failure state return observations are available, there are severe problems in interpreting them. In the fiscal period in which a firm enters bankruptcy, total costs are partly composed of operating costs and partly of costs associated with the bankruptcy itself. To separate out these costs requires a detailed analysis of accounting statements at a level of disaggregation not available on machine-readable data bases. For present purposes it is essential to separate these costs, however, since operating return realizations, $\mathrm{x}$, and bankruptcy costs, $\gamma$, are separate variables.

A detailed firm-by-firm analysis was beyond the scope of this study, and therefore an alternative approach was employed. Knowing that our sample included no observations for firms which had failed, we assumed that the lowest observed sample return in each industry, $x_{\min }$, was at the boundary of "bankruptcy." In other words, we assumed that $x_{\min }$ was the upper bound on the range of return states in which a firm with ordinary debt outstanding would be monitored. This is a simplification because the decision to monitor or declare "bankruptcy" depends not only on the return realization, $\mathrm{x}$, but also on the monitoring cost $\gamma$. Further, for purposes of estimating return distributions, we are assuming sample firms employed standard debt contracts. This seems empirically reasonable. The lower bound on the range of these return states was assumed to be -1.0 , that is, the case in which the firm is worthless. 
The "bankruptcy" range was split into several discrete return states, as was done for the "nonbankruptcy" range. Figure 1 pictures a return distribution constructed in this matter for some hypothetical industry. We assumed that each discrete return state in the "bankruptcy" range was equi-probable. This is a conservative assumption since it seems likely that, in reality, probability mass is greater to the right side of the "bankruptcy" range than to the left. Finally, probabilities of "nonbankruptcy" states were adjusted downward so that the sum of all state probabilities equaled one.

We chose the probability of falling somewhere in the "bankruptcy" range to be the national average annual failure rate for nonfinancial firms over the period 1972-91 (as reported in the Annual Report of the President, 1992). Our "best guess" estimate was simply this average, which was $0.677 \%$. We also report a calibration based on a "conservative estimate," where the probability of "bankruptcy" was three times the national average failure rate.

All results reported in this study are obtained with two discrete "bankruptcy" states. However, we also experimented with economies where the "bankruptcy" range was partitioned into four discrete states. Results based on the finer partition did not differ substantively from those reported.

\section{E. Numerical Solutions}

The problems (P.2) and (P.3) were solved, using the calibrated values we have described, by transforming them into either linear programming problems or a sequence of linear programming problems. In such a problem there are 132 incentive 
constraints (with 12 states). This proliferation of incentive constraints dictates that the number of discrete return states be kept relatively small, as we have done.

\section{Calibration Results}

Figure 2 displays qualitative properties of the solutions to (P.2) and (P.3) for the mining industry. The figure was obtained using our "best estimate" parameter values. (The complete solutions to (P.2) and (P.3) for this example are shown in table 2.) Panel $\mathrm{A}$ in figure 2 shows the net resources retained by borrowers under (P.2) when monitoring does (does not) occur in each state. It also displays the net resources retained by the borrower in each state in the solution to the nonstochastic monitoring problem (P.3). Panel B shows the expected return to the borrower, contingent on being in state $i$, in the solutions to (P.2) and (P.3). Finally, panel C displays the optimal monitoring probabilities ( $\left.\mathrm{p}_{\mathrm{i}}\right)$ in each state for (P.2) and (P.3).

As is apparent, in states that set $\mathrm{p}_{\mathrm{i}}=0$ under (P.2), the return to the borrower is virtually identical whether monitoring is stochastic or not (panel A). The expected return to the borrower, conditional on being in state $\mathrm{i}$, also differs by a relatively small amount in the solutions to (P.2) and (P.3) (panel B). Finally we note that the state contingent expected returns to the borrower are monotonically increasing under (P.2) and monitoring probabilities are monotonically decreasing -as the Border and Sobel theorem asserts.

Panel A clearly displays the contractual debt forgiveness associated with solutions to the problem (P.2). In states 1-6 monitoring occurs with positive probability under (P.2). When monitoring occurs, the borrower retains something in states 2-6. Moreover, the borrower retains something even if monitoring does not 
occur in states 4-6. This example also displays strong contractual debt forgiveness. In particular, it is feasible for the borrower to repay principal plus interest in states 4,5 , and 6 . However, even though it is feasible for the borrower to fully repay in these states, he does not do so, and still retains positive quantities of resources (whether monitoring occurs or not). Similar results were obtained for many of the industries and parameter combinations that we examined. Thus strong contractual debt forgiveness would appear to be widely desirable, rather than just a theoretical possibility. In other words, for reasonable parameter values, strong contractual debt forgiveness seems often to be optimal.

Also, as is clear from figure 2, even though contractual debt forgiveness and strong contractual debt forgiveness are optimal, the optimal contracts do resemble standard debt contracts in a variety of respects. This is particularly apparent in panel B of figure 2: the expected returns to the borrower-state by state-are close, either with or without stochastic monitoring.

\section{A. Losses Due to Universal Imposition of Standard Debt Contracts}

We now report the estimated deadweight losses if the use of standard debt contract is exogenously and suboptimally imposed. Table 3 reports this deadweight loss for each industry - which is just the difference between the maximized objectives in (P.2) and (P.3). For each industry we report results with both the "best guess" and "conservative" parameters.

Panel A (in table 3) shows the deadweight loss expressed as a fraction of the expected monitoring cost in the solution to (P.3) (nonstochastic monitoring). In effect, this represents the percentage reduction in monitoring costs due to stochastic 
monitoring. That reduction is typically substantial, averaging around $50 \% .^{9}$ Panel B shows deadweight loss expressed as a fraction of the net project return; that is, how much higher the net project return would have to be to offset the deadweight loss associated with the suboptimal use of standard debt. This fraction is typically small, averaging about $0.1 \%$ with best guess parameters and about $0.9 \%$ with conservative parameters. (However, it varies considerably across industries, and is as high as $2.5 \%$ with conservative parameters.) Finally, panel $\mathrm{C}$ expresses deadweight loss as a fraction of initial total assets; e.g., the percentage reduction in the initial value of the firm due to imposing the use of standard debt contracts. Expressed this way deadweight loss is very small indeed, representing $0.01 \%$ on average with best guess parameters, and $0.07 \%$ on average with conservative ones.

In sum, the calibration exercise suggests that stochastic monitoring can substantially reduce expected monitoring costs. However, with reasonable parameter values, expected monitoring costs are themselves very small relative to project returns, and smaller still relative to firm assets. Thus, if there are any costs that are at all substantial (or any incentive problems) associated with stochastic monitoring-such stochastic monitoring is unlikely to be observed. Our results therefore may provide an explanation for why stochastic monitoring is so rarely observed in financial contracting. ${ }^{10}$

Finally, in order to evaluate the size of our estimated deadweight losses due to the suboptimal use of standard debt contracts, it is interesting to compare them with other estimates of deadweight losses from the public finance literature. Cooley and Hansen (1989), for instance, estimate the welfare cost of a permanent $10 \%$ inflation in the United States to be about $0.4 \%$ of GNP. Browning (1976) estimates 
the marginal excess burden of income taxation in the United States to be 9 cents on the dollar. Stuart (1984) obtains a similar estimate, while Ballard, Shoven, and Whalley (1985) estimate marginal excess burden in the United States to be 15 cents on the dollar. Other estimates are substantiaily higher. These flow measures of deadweight loss are, perhaps, best compared with panel $\mathrm{B}$ in table 3 . The welfare losses due to the (suboptimal) imposition of standard debt contracts appear quite small when compared to the welfare losses that result from the imposition of virtually any tax that is currently widely employed in the United States.

\section{v. Conclusion}

We have considered ex ante contracts in an idealized world where contracts can specify a complete set of state contingencies, and where there are no difficulties of implementation or enforcement associated with contractual provisions. We have found that standard debt contracts are not optimal in such a world, at least for any reasonable assumptions about parameter values. Indeed, optimal contracts call for the randomized initiation of bankruptcy proceedings. The borrower (or junior claimant) "does better" when bankruptcy proceedings are initiated. And optimal contracts specify ex ante contingencies calling for some degree of debt forgiveness.

It may be objected that these contractual features do not seem to be observed in actual contracts, and hence are odd. To a substantial extent we do not disagree. ${ }^{11}$ Rather, we believe that standard debt contracts are "nearly optimal" in our idealized world. Indeed, our results suggest that the gains due to stochastic monitoring are small, at least when reasonable exogenous parameter values are employed. Thus, if there are significant costs or incentive problems associated with randomized 
monitoring, it is unlikely to be employed. This finding may give some comfort to the many researchers who have, for tractability, ruled out randomization. By implication, the welfare gains associated with deviating from standard debt contracts are small, too. 


\section{References}

Aghion, P.; Hart, O.; and Moore, J. 1992. The economics of bankruptcy reform. Journal of Law, Economics, and Organization 8 (October): 523-46.

Allen, F., and Gale, D. 1992. Measurement distortion and missing contingencies in optimal contracts. Economic Theory 2 (January): 1-26.

Altman, E. I. 1984. A further empirical investigation of the bankruptcy cost question. Journal of Finance 39 (September): 1067-89.

Ballard, C. L.; Shoven, J. B.; and Whalley, J. 1985. General equilibrium computations of the marginal welfare costs of taxes in the United States. American Economic Review 75 (March): 128-38.

Berlin, M., and Mester, L. J. 1992. Debt covenants and renegotiation. Journal of Financial Intermediation 2 (June): 95-133.

Bernanke, B., and Gertler, M. 1989. Agency costs, net worth, and business fluctuations. American Economic Review 79 (March): 14-31.

Border, K. C., and Sobel, J. 1987. Samurai accountant: A theory of auditing and plunder. Review of Economic Studies 54 (October): 525-40.

Boyd, J. H., and Smith, B. D. 1993. The equilibrium allocation of investment capital in the presence of adverse selection and costly state verification. Economic Theory 3: 427-51.

Browning, E. K. 1976. The marginal cost of public funds. Journal of Political Economy 84 (April): 283-98.

Chang, C. 1990. The dynamic structure of optimal debt contracts. Journal of Economic Theory 52 (October): 68-86. 
Cooley, T. F., and Hansen, G. D. 1989. The inflation tax in a real business cycle model. American Economic Review 79 (September): 733-48.

Diamond, D. W. 1984. Financial intermediation and delegated monitoring. Review of Economic Studies 51 (July): 393-414.

Gale, D., and Hellwig, M. 1985. Incentive-compatible debt contracts: The oneperiod problem. Review of Economic Studies 52 (October): 647-63.

Harris, M., and Raviv, A. 1991. The theory of capital structure. Journal of Finance 46 (March): 297-355.

Harris, M., and Raviv, A. 1992. The design of bankruptcy procedures. Unpublished manuscript. Northwestern University.

Krasa, S., and Villamil, A. P. 1991. Optimal contracts with costly state verification: The multilateral case. BEBR Working Paper 91-0127. University of Illinois at Urbana-Champaign.

Mookherjee, D., and Png, I. 1989. Optimal auditing, insurance, and redistribution. Quarterly Journal of Economics 104 (May): 399-415.

Oh, S.-N., and Green, E. J. 1992. The consumption process implied by an efficient credit contract. Research Department Working Paper 499. Federal Reserve Bank of Minneapolis.

Stuart, C. E. 1984. Welfare costs per dollar of additional tax revenue in the United States. American Economic Review 74 (June): 352-62.

Townsend, R. M. 1979. Optimal contracts and competitive markets with costly state verification. Journal of Economic Theory 21 (October): 265-93. 
Townsend, R. M. 1988. Information constrained insurance: The revelation principle extended. Journal of Monetary Economics 21 (March/May): 411-50.

Warner, J. B. 1977. Bankruptcy costs: Some evidence. Journal of Finance 32 (May): 337-47.

White, M. J. 1983. Bankruptcy costs and the new bankruptcy code. Journal of Finance 38 (May): 477-88.

Williamson, S. D. 1986. Costly monitoring, financial intermediation, and equilibrium credit rationing. Journal of Monetary Economics 18 (September): 159-79.

Williamson, S. D. 1987. Costly monitoring, loan contracts, and equilibrium credit rationing. Quarterly Journal of Economics 102 (February): 135-45.

Winton, A. 1992. Costly state verification and multiple investors: The role of seniority. Department of Finance Working Paper 120. Northwestern University. 
Footnotes

*We thank Doug Diamond, Ed Green, Ellen McGrattan, Janet Mitchell, John Moore, Andy Winton, and an anonymous referee for helpful comments, with the usual disclaimer absolving them from responsibility for remaining errors. Joel Krueger provided excellent computational assistance. The views expressed herein are those of the authors and not necessarily those of the Federal Reserve Bank of Minneapolis or the Federal Reserve System.

${ }^{1}$ This result has been extended by Krasa and Villamil (1991) and Winton (1992) to allow for some risk aversion, by Boyd and Smith (1993) to allow for heterogeneity (and private information) about borrower type, and by Chang (1990) to allow for multi-period contracts.

${ }^{2}$ Harris and Raviv (1992) note that U.S. bankruptcy courts often leave borrowers with some assets as part of a negotiated bankruptcy settlement.

${ }^{3}$ The CESV environment is probably most appropriate for the investigation of publicly traded claims. First, for traded corporate bonds, with hundreds or thousands of holders, out-of-court renegotiation is extremely difficult. Second, as the CESV model emphasizes, bankruptcy proceedings do result in out-of-pocket costs, and an important part of bankruptcy proceedings is to discover the true value of the firm. By contrast, bank loans and credit facilities are different in a variety of regards, most of which facilitate out-of-court renegotiation. For an excellent analysis of these issues, see Berlin and Mester (1992).

${ }^{4}$ Some, but not all, of these results appear in Border and Sobel (1987). They did not consider a financial contracting version of their environment, however, and 
the implications of their results for optimal financial contracts appear to have been largely overlooked.

${ }^{5}$ For a statement of the "revelation principle" in this environment see Border and Sobel (1987).

${ }^{6}$ Border and Sobel were not primarily concerned with a borrowing/lending interpretation of their environment, and hence did not emphasize that contractual debt forgiveness could occur. The possibility of strong contractual debt forgiveness was not discussed by Border and Sobel.

${ }^{7}$ Much higher estimates of $\gamma$ are reported in some studies, but these include "indirect" as well as direct costs of bankruptcy. So-called indirect costs represent lost sales, increased borrowing costs, foregone investment opportunities, and so on. By construction, these can be experienced by weak firms which do not actually fail (Altman 1984), as well as those which do. Clearly, such indirect costs are largely transfer payments, not dead-weight losses, and do not belong in the parameter $\gamma$ employed here.

Also, by allowing $\gamma$ to be as high as $10 \%$ of assets, we believe we are making ample allowance for the potential existence of unobserved losses due to delays in bankruptcy arising from strategic interactions among parties to the contract.

${ }^{8}$ Firms which perform poorly over a period of several years are likely to be dropped by Compustat, even if they do not actually go into bankruptcy. (Compustat is largely marketed to investors, who may lose interest in firms which are suffering losses, shrinking, having their shares delisted, etc.) For that reason, $\mathbf{x}_{\min }$ is likely to be larger than the actual cut-off return for bankruptcy. The data suggest that this is often the case. Using $\mathrm{x}_{\min }$ as the cut-off return is a conservative procedure for our 
purposes, since it makes bankruptcy realizations at least as common in the model as they are in reality.

${ }^{9}$ In some industries, the "conservativen ${ }^{n}$ deadweight loss computation is less than the "best guess" one in panel $\mathrm{A}$. This occurs because the conservative assumptions increase both the probability of bad states and the cost of monitoring. This raises both the numerator and denominator in panel $\mathrm{A}$.

${ }^{10}$ Our result is similar in spirit to that of Oh and Green (1992). They compare two infinite horizon partial-equilibrium models. In one, agents are restricted to employing noncontingent, dated, wealth claims. In the other, they can write a full range of contingent contracts. The two models are calibrated and solved numerically. The conclusion is that the welfare loss due to restricting the set of feasible contracts is small.

"We are not sure that it is necessarily so odd that borrowers may be better off if bankruptcy proceedings are initiated than if they are not. Often financially distressed borrowers do "seek the protection" of the bankruptcy courts. And also, substantial bargaining power is sometimes given to incumbent management in bankruptcy in the form of the temporary right to propose reorganization plans. Finally, some literature suggests that incumbent management enjoys private, nontransferable benefits from remaining in control of a firm's assets during the interval until the resolution of the bankruptcy proceedings. 
Table 1:

Gross Returns to Assets, $x^{1}$

Compustat Annual Data 1972-1991

\begin{tabular}{|c|c|c|c|c|c|c|}
\hline 15 Building Contractors & 377 & .1117 & .11052 & .07557 & .06781 & .306 \\
\hline 16 Heavy Construction & 189 & .0634 & .06093 & .11277 & .11354 & .494 \\
\hline 25 Furniture & 192 & .1561 & .15502 & .06459 & .06406 & .584 \\
\hline 26 Paper and Allied Products & 508 & .1202 & .11910 & .06714 & .06900 & .462 \\
\hline 34 Fabricated Metal Products & 540 & .1213 & .12083 & .09759 & .10090 & .501 \\
\hline 38 Technical and Photographic Equipment & 524 & .1217 & .12025 & .07958 & .08098 & .505 \\
\hline
\end{tabular}

Note: The transformed data is the actual data divided into 10 intervals of equal length. Each interval's mean is used to calculate the grand mean for each industry. The standard deviation is calculated in a similar fashion.

'The variable we use, $x$, is calculated as follows with the appropriate Compustat data field in parentheses:

$x=($ Income $(172)+$ Taxes $(16)+$ Interest (15))/Assets (6) 
Table 2:

Complete Solutions to Problems P.2 and P.3:

Mining Industry, "Best Guess” Parameters*

\begin{tabular}{|c|c|c|c|c|c|c|c|}
\hline \multicolumn{6}{|c|}{ Choice Variables } & \multicolumn{2}{|c|}{ Return Distribution } \\
\hline State & $\mathrm{p}$ & $x-t$ & $x-f$ & $\mathrm{t}$ & $f-\gamma$ & h & $\mathbf{x}$ \\
\hline \multicolumn{8}{|c|}{ Solution to Problem P.2 } \\
\hline 1 & .712 & .000 & .000 & .056 & .021 & .003 & .056 \\
\hline 2 & .491 & .000 & .065 & .167 & .067 & .003 & .167 \\
\hline 3 & .265 & .000 & .260 & .295 & .000 & .011 & .295 \\
\hline 4 & .157 & .088 & .402 & .349 & .000 & .007 & .437 \\
\hline 5 & .072 & .184 & .545 & .396 & .000 & .011 & .580 \\
\hline 6 & .027 & .305 & .688 & .418 & .000 & .011 & .723 \\
\hline 7 & .000 & .435 & - & .430 & - & .052 & .865 \\
\hline 8 & .000 & .578 & - & .430 & - & .399 & 1.008 \\
\hline 9 & .000 & .721 & - & .430 & - & .380 & 1.151 \\
\hline 10 & .000 & .863 & - & .430 & - & .089 & 1.294 \\
\hline 11 & .000 & 1.006 & - & .430 & - & .026 & 1.436 \\
\hline 12 & .000 & 1.149 & - & .430 & - & .007 & 1.579 \\
\hline \multicolumn{8}{|c|}{ objective function $=.6457488$} \\
\hline
\end{tabular}

\section{Solution to Problem P.3}

$\begin{array}{llllllll}1 & 1.000 & .000 & .000 & - & .021 & .003 & .056 \\ 2 & 1.000 & .000 & .000 & - & .132 & .003 & .167 \\ 3 & 1.000 & .000 & .000 & - & .260 & .011 & .295 \\ 4 & .000 & .010 & - & .428 & - & .007 & .437 \\ 5 & .000 & .152 & - & .428 & - & .011 & .580 \\ 6 & .000 & .295 & - & .428 & - & .011 & .723 \\ 7 & .000 & .438 & - & .428 & - & .052 & .865 \\ 8 & .000 & .580 & - & .428 & - & .399 & 1.008 \\ 9 & .000 & .723 & - & .428 & - & .380 & 1.151 \\ 10 & .000 & .868 & - & .428 & - & .089 & 1.294 \\ 11 & .000 & 1.009 & - & .428 & - & .026 & 1.436 \\ 12 & .000 & 1.151 & - & .428 & - & .007 & 1.579\end{array}$

objective function $=.6454483$

${ }^{*} \gamma=0.035, h_{1}+h_{2}=0.677 \%$ (arnual average "bankruptcy" rate), $R=0.4235$. 
Table 3:

Estimates of the Cost of Imposing Absolute Priority

[Difference Between the Solution to Problem P.3 (Nonstochastic Monitoring) and P.2 (Stochastic Monitoring)]

\begin{tabular}{|c|c|c|c|c|c|c|}
\hline \multirow{4}{*}{ Parameters ${ }^{5}$ : } & \multicolumn{6}{|c|}{ Expressed as a Percent of: } \\
\hline & \multicolumn{2}{|c|}{$\begin{array}{l}\text { (A) Expected Monitoring Cost } \\
\text { With Solution to P. } 3^{2}\end{array}$} & \multicolumn{2}{|c|}{$\begin{array}{c}\text { (B) Expected } \\
\text { Net Project Return }\end{array}$} & \multicolumn{2}{|c|}{ (C) Initial Total Assets } \\
\hline & "Best Guess" & "Conservative" & "Best Guess" & "Conservative" & "Best Guess" & "Conservative" \\
\hline & & & & & & \\
\hline Mining & $48.09563 \%$ & $-^{\circ}$ & $.43167 \%$ & - & $.03005 \%$ & - \\
\hline Building Contractors & 44.69791 & $47.94295 \%$ & .10004 & $1.01019 \%$ & .01062 & $.09730 \%$ \\
\hline Heavy Construction & 57.68272 & 56.85084 & .24383 & 2.49861 & .01365 & .11537 \\
\hline Lumber and Wood Products & 36.65876 & 35.03654 & .03834 & .34306 & .00437 & .03556 \\
\hline Furniture & 69.12364 & 68.29995 & .05438 & .49000 & .00819 & .06934 \\
\hline Paper and Allied Products & 34.77993 & 34.55793 & .03599 & .33404 & .00414 & .03508 \\
\hline Fabricated Metal Products & 55.84541 & 57.49857 & .11471 & 1.12038 & .01317 & .11673 \\
\hline Technical and Photographic Equipment & 27.98837 & 29.04213 & .02880 & .28153 & .00340 & .02952 \\
\hline Utilities & 56.90617 & 56.68214 & .14657 & 1.38251 & .01351 & .11506 \\
\hline Eating and Drinking Places & 26.43709 & 30.24072 & .02151 & .22788 & .00315 & .03068 \\
\hline Mean & 45.80000 & 46.30000 & .12100 & .85300 & .01000 & .07200 \\
\hline
\end{tabular}

'In all entrics, the numeralor is $\gamma\left(\Sigma_{i}^{3} p_{1}^{3} h_{1}-\Sigma_{p_{i}}^{2} h_{1}\right)$, where the superscript $k$ indicates the solution to problem $k$.

${ }^{2}$ Denominalor is $\gamma \Sigma_{p} p_{i}^{3}$.

${ }^{3}$ Denominator is $\Sigma_{i} x_{i} h_{i}-1.0$.

'Denominator is 1.0 aince initial aysels are nonnalized to 1,0 .

"Best Guess" = most likely parameters. $\gamma=3.5 \%, h_{1}+h_{2}=0.677 \%$. "Conservative" parameters: $\gamma=10 \%, h_{1}+h_{2}=2.031 \%$.

"For this sed of parameler values, "banksuptcy" costs exceed project returns in the word stale, which violates a nonnegativity constraint. Solution cannot be obtained. 
FIGURE 1

ESTIMATED DISTRIBUTION OF RETURNS, $x$ FOR A HYPOTHETICAL INDUSTRY ${ }^{[1]}$

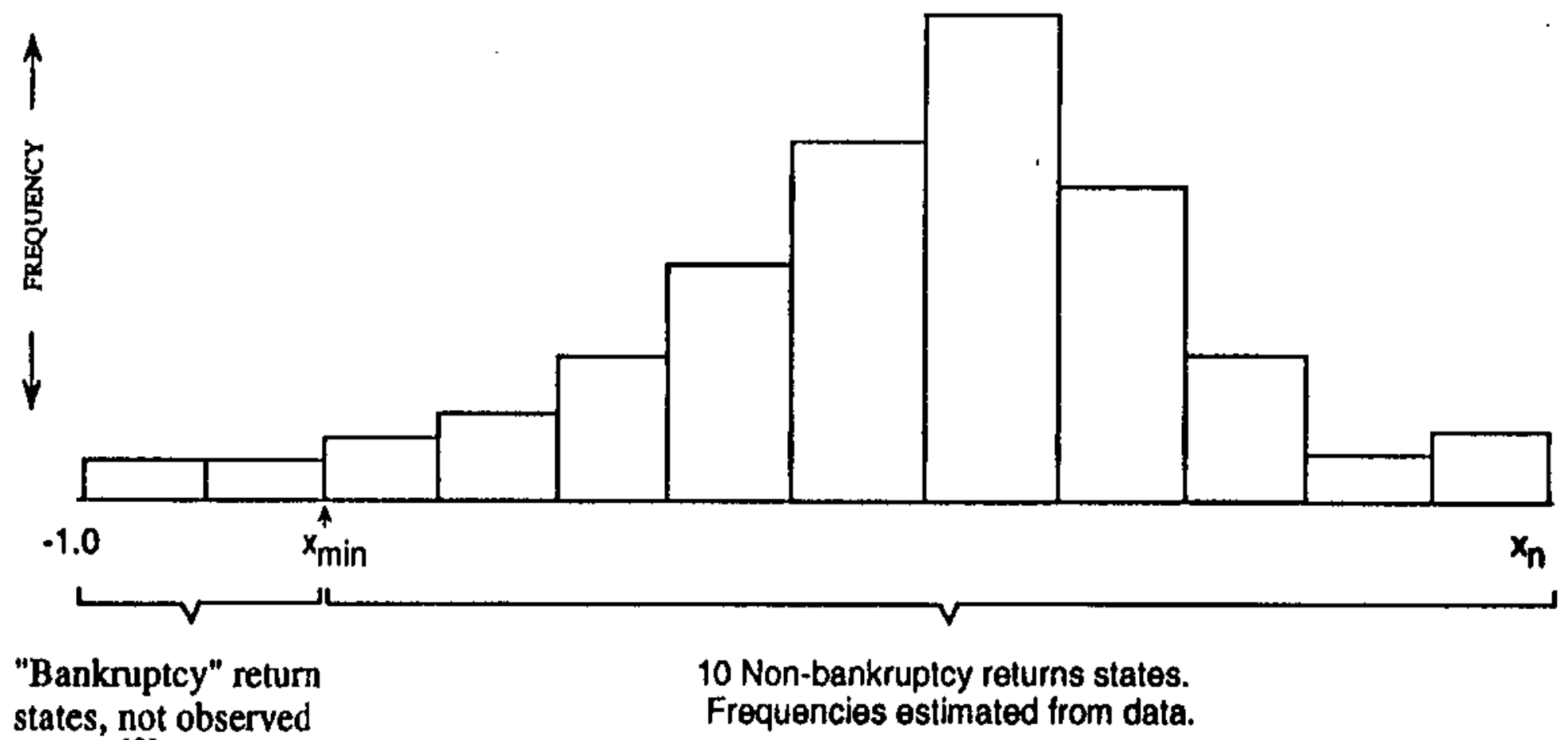

in data. $[2]$

[1] $\mathbf{x}=$ [Net Income After Taxes + Interest Expense + Taxes]/Total Assets

[2] Frequency based on national average failure rates for non-financial firms, 1972-1991.

$\mathbf{x}_{\mathbf{n}}\left(\mathbf{x}_{\mathbf{m i n}}\right)=$ highest (lowest) return realization observed in sample data. 
FIGURE 2

\section{SOLUTIONS TO P.2 AND P.3: \\ FEATURES OF THE OPTIMAL CONTRACTS}

(1)

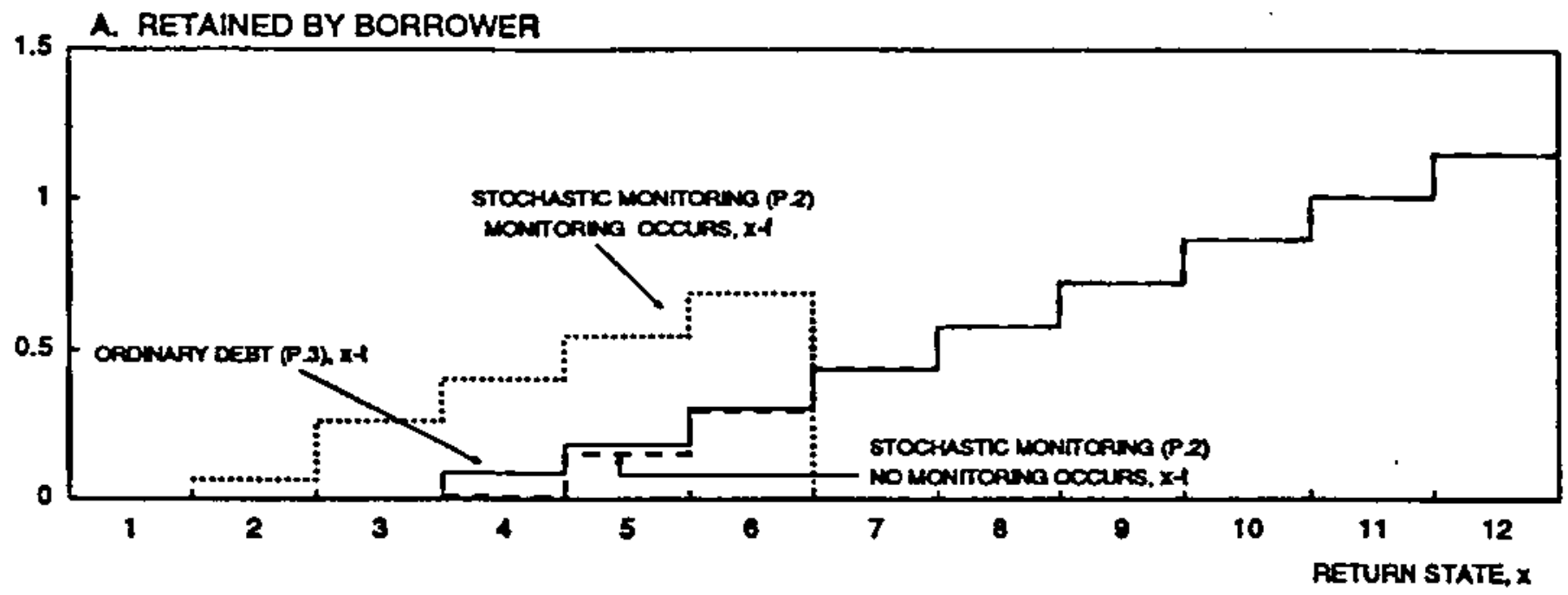

B. EXPECTED RETURNS TO BORROWER, BY STATE

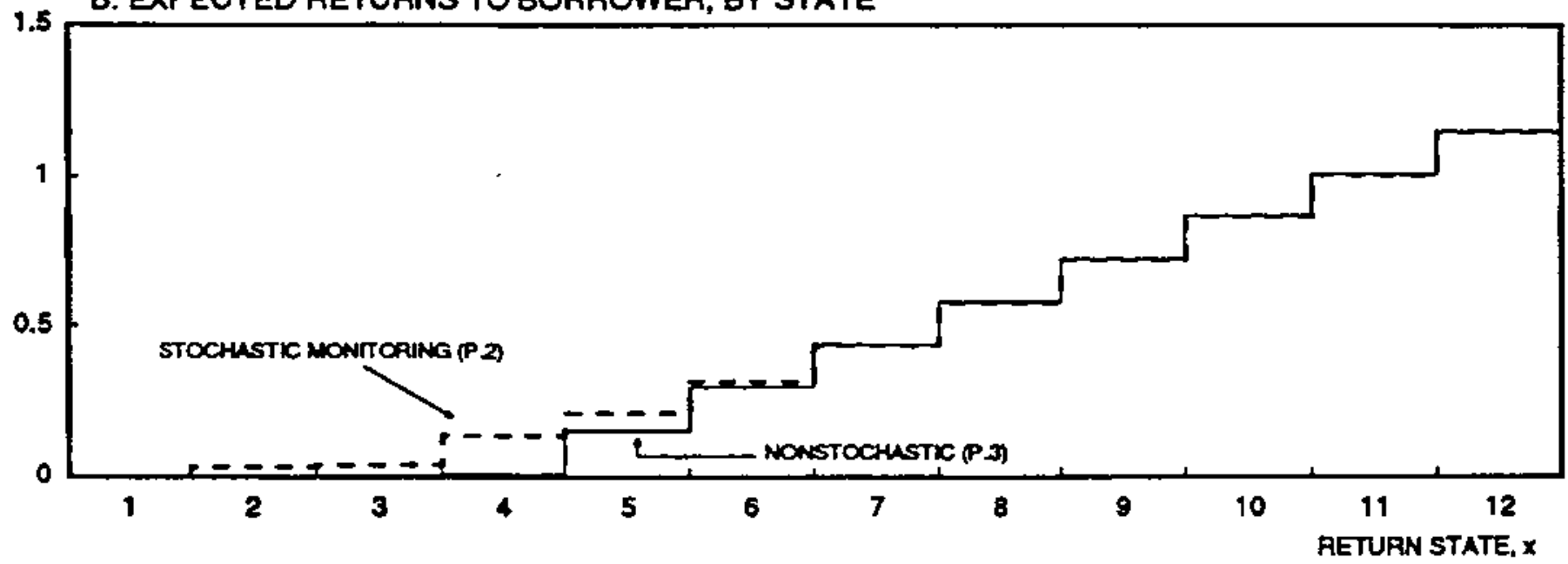

C. MONITOR PROBABILITIES, p

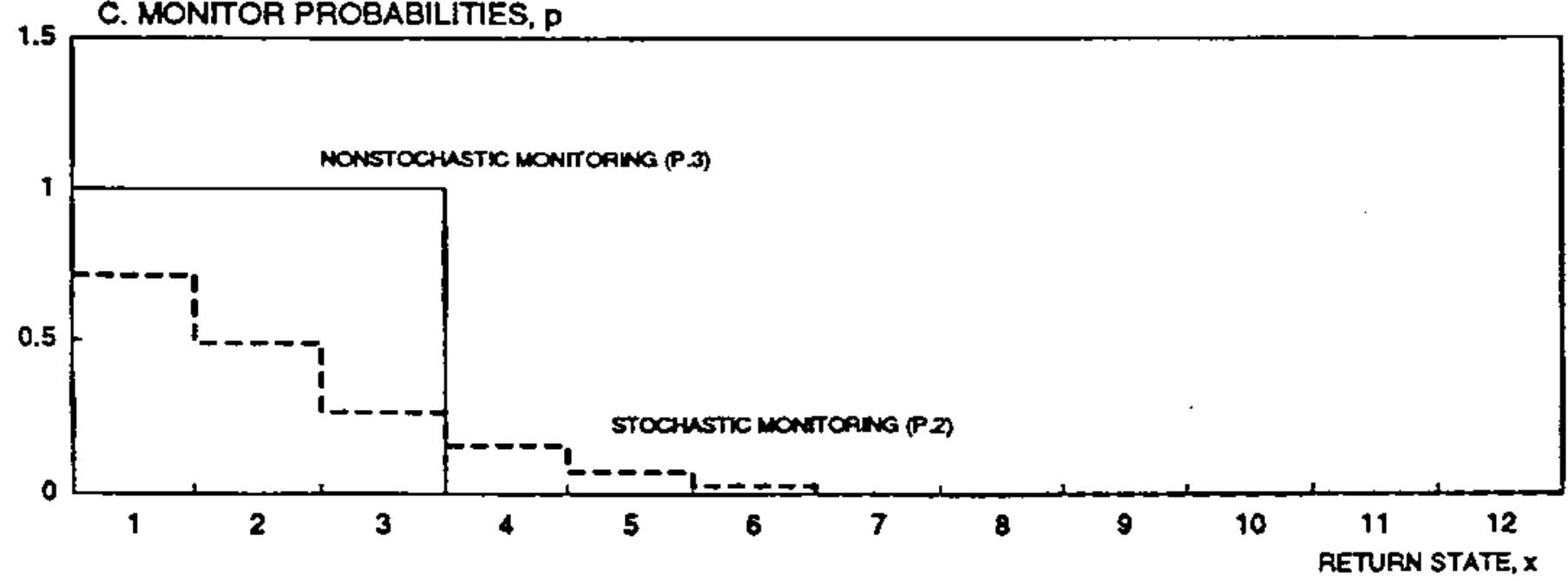

(1) The Optimal contracts for industry 10, Mining, assuming the "best guess" parameters, $\gamma=3.5 \%$, $h_{1}+h_{2}=.677 \%$. 